Prepared for U.S. Fish and Wildlife Service, Agreement: G12AC2009

\title{
An Individual-Based Model for Predicting Dynamics of a Newly Established Mexican Wolf (Canis lupus baileyi) Population-Final Report
}

Open-File Report 2018-1126 



\section{An Individual-Based Model for Predicting Dynamics of a Newly Established Mexican Wolf (Canis Iupus baileyi) Population-Final Report}

By Jay V. Gedir and James W. Cain III

Prepared for U.S. Fish and Wildlife Service, Agreement: G12AC20098

Open-File Report 2018-1126

U.S. Department of the Interior

U.S. Geological Survey 


\section{U.S. Department of the Interior \\ RYAN K. ZINKE, Secretary}

\section{U.S. Geological Survey James F. Reilly II, Director}

U.S. Geological Survey, Reston, Virginia: 2018

For more information on the USGS-the Federal source for science about the Earth, its natural and living resources, natural hazards, and the environment-visit https://www.usgs.gov/ or call 1-888-ASK-USGS.

For an overview of USGS information products, including maps, imagery, and publications, visit https:/store.usgs.gov.

The findings and conclusions in this article are those of the author(s) and do not necessarily represent the views of the U.S. Fish and Wildlife Service.

Any use of trade, firm, or product names is for descriptive purposes only and does not imply endorsement by the U.S. Government.

Although this information product, for the most part, is in the public domain, it also may contain copyrighted materials as noted in the text. Permission to reproduce copyrighted items must be secured from the copyright owner.

Suggested citation:

Gedir, J.V., and Cain, J.W., III, 2018, An individual-based model for predicting dynamics of a newly established Mexican wolf (Canis lupus baileyi) population-Final report: U.S. Geological Survey OpenFile Report 2018-1126, 16 p., https://doi.org/10.3133/ofr20181126.

IISSN 2331-1258 (online) 


\section{Contents}

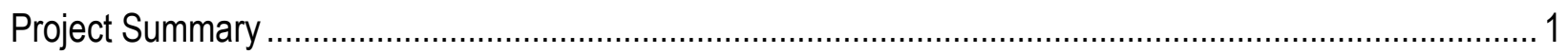

Project Methods

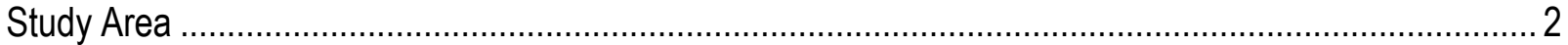

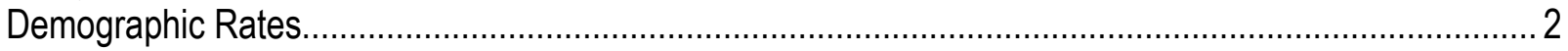

Population Models...................................................................................................................

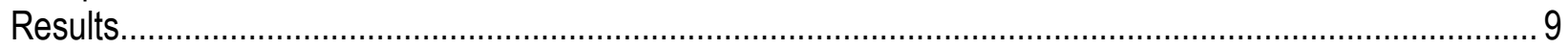

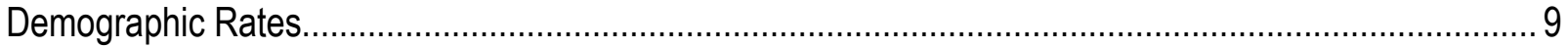

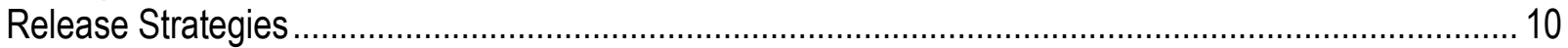

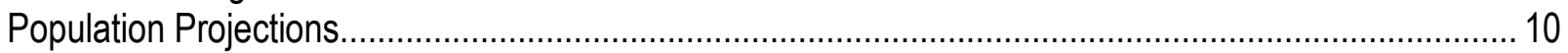

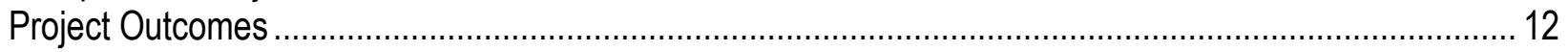

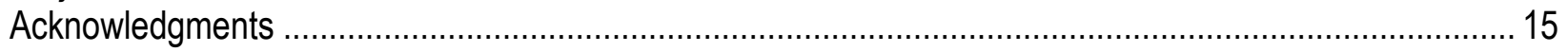

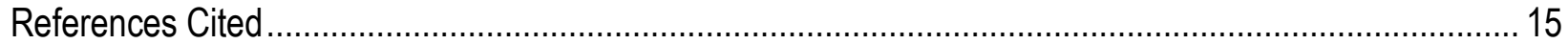

\section{Figures}

Figure 1. Mexican Wolf Experimental Population Area (MWEPA) and Blue Range Wolf Recovery Area (BRWRA) in eastern Arizona and western New Mexico from 1998 to 2014.

Figure 2. Number of wolves (minimum), wolf releases from captivity and wolf removals (lethal or to captivity) and translocations in the Mexican wolf reintroduction to the Blue Range Wolf Recovery Area in Arizona and New Mexico, USA, 1998-2017.

Figure 3. Mexican wolf population sizes (solid lines) and 95 percent confidence intervals (dashed lines) projected from individual-based models using data from Mexican wolves reintroduced to the Blue Range Wolf Recovery Area 1998-2014 in New Mexico and Arizona, USA, for released wolves that were (a) captive-born and (b) wild-born, and when problem wolves were managed through (c) removals and (d) diversionary feeding.

\section{Table}

Table 1. Mean survival probabilities (variance in parentheses; $n=219$ wolves) and pup recruitment rates ( \pm standard error; $n=146$ potential litters) used in wolf population projection models, from IMexican wolves reintroduced to the Blue Range Wolf Recovery Area, New Mexico and Arizona, 1998-2014. 


\section{Conversion Factors}

International System of Units to U.S. customary units

\begin{tabular}{lcll}
\hline & Multiply & By & \multicolumn{1}{c}{ To obtain } \\
\hline & Length & & \\
\hline meter $(\mathrm{m})$ & 3.281 & foot $(\mathrm{ft})$ \\
kilometer $(\mathrm{km})$ & 0.6214 & mile $(\mathrm{mi})$ & \\
\hline & Area & \\
\hline square kilometer $\left(\mathrm{km}^{2}\right)$ & 0.3861 & square mile $\left(\mathrm{mi}^{2}\right)$ \\
\hline
\end{tabular}




\title{
An Individual-Based Model for Predicting Dynamics of a Newly Established Mexican Wolf (Canis lupus baileyi) Population-Final Report
}

\author{
By Jay V. Gedir ${ }^{1}$ and James W. Cain III²
}

\section{Project Summary}

The Mexican wolf recovery team proposed to establish other populations of Mexican wolves (Canis lupus baileyi) in the Southwest (U.S. Fish and Wildlife Service, 1982). We were tasked to conduct an extensive simulation modeling exercise to determine release strategies (in conjunction with management actions) that best predict establishment of a new Mexican wolf population. Our objectives were to determine optimal release and management strategies for population establishment and growth. This is a retrospective analysis utilizing data from 1998 to 2014, and during this period, we divided management strategies into two phases; (1) 1998-2008, where nuisance wolves (i.e., wolves that exhibit nuisance behavior or depredate livestock) were managed primarily through lethal removals and removals to captivity, and (2) 2009-2014, when lethal removals ceased and diversionary feeding was provided to denning packs to dissuade wolves from conflict with humans. Management strategies from the second phase are being used for management of the current Mexican wolf population, and demographic rates derived from alternate population modeling in Vortex incorporating post-2008 wolf data are being used to guide future recovery efforts. Therefore, demographic rates estimated from our retrospective analysis will differ (i.e., due to our unique approach to the analyses and the demographic rates being derived from a different dataset), and are intended solely to address the objectives of this report, and are not intended as basis for the development of management recommendations for the current Mexican wolf population. Using individual-based models, we tested dozens of scenarios and derived an optimal release strategy that had the highest probability of establishing a new population and which maximized subsequent post-release growth, and in this report, we present these model results. Findings from this research will improve our understanding of release strategies that yield growing populations, advance our understanding of the demands of reintroducing large carnivores, and provide insight into beneficial strategies that could aid other species reintroduction programs.

\footnotetext{
${ }^{1}$ New Mexico State University_-Department of Fish, Wildlife and Conservation Ecology.

${ }^{2}$ U.S. Geological Survey.
} 


\section{Project Methods}

\section{Study Area}

The Mexican wolf reintroduction program in the United States was established from seven founders (Hedrick and others, 1997), and reintroductions into the former Blue Range Wolf Recovery Area (BRWRA; fig. 1) began with the release of 13 wolves in 1998, and as of the end of 2017, the estimated minimum population was 114 wolves (fig. 2; U.S. Fish and Wildlife Service, unpub. data, 2017). The BRWRA encompassed $17,752 \mathrm{~km}^{2}$ of rugged mountains, elevated mesas, deep canyons and semi-desert lowlands in west-central New Mexico and east-central Arizona (U.S. Fish and Wildlife Service, 1996). Elevations range from 1,100 to 3,400 m, with scrublands and mixed conifer stands at the lower and higher elevations, respectively; ponderosa pine (Pinus ponderosa) dominates most of the study area. In the BRWRA, wolves primarily prey on elk (Cervus canadensis) and to a lesser extent mule deer (Odocoileus hemionus) and Coues' white-tailed deer (O. viginianus couesi), while other potential prey species include bighorn sheep (Ovis canadensis), collared peccary (Pecari tajacu), pronghorn (Antilocapra americana) and lagomorphs, as well as other small prey (Reed and others, 2006; Carrera and others, 2008; Merkle and others, 2009). Domestic livestock grazing occurs across most of the BRWRA, and thus, cattle are a secondary prey item for wolves (Reed and others, 2006; Carrera and others, 2008; Merkle and others, 2009).). Other predators that occur within the BRWRA are mountain lion (Puma concolor), black bear (Ursus americanus), bobcat (Lynx rufus), coyote (Canis latrans) and grey fox (Urocyon cinereoargenteus; U.S. Fish and Wildlife Service, 1993).

\section{Demographic Rates}

This is a retrospective analysis, and therefore wolf demographic rates for the models were derived using data from the BRWRA reintroduction from 1998 to 2014. During this period, we divided strategies for managing problem wolves (i.e., wolves that exhibit nuisance behavior or depredate livestock) into two phases. From 1998 to 2008, problem wolves were sometimes captured and translocated out of the offending area, but more often they were lethally removed or removed to captivity; there was an increase in removals occurring from 2003 to 2008 (fig.2). Starting in 2009, the removal of problem wolves largely ceased due to a court order, and the USFWS began providing native-prey carcasses, horse meat or commercially produced carnivore food to packs in efforts to reduce livestock depredation (i.e., diversionary feeding; fig. 2). Diversionary feeding may also assist adults in raising additional pups, although that was not the primary purpose of the efforts. Diversionary feeding is primarily used when wolves are raising a litter (i.e., mid-April or May through late August or early September, or when the pack ceased utilizing the food), because their movements are more predictable at this time, predation rates are higher due to provisioning of young, and whelping coincides with cattle calving season. This practice is rarely conducted during winter, because wolves exhibit more extensive movements across their territory. 


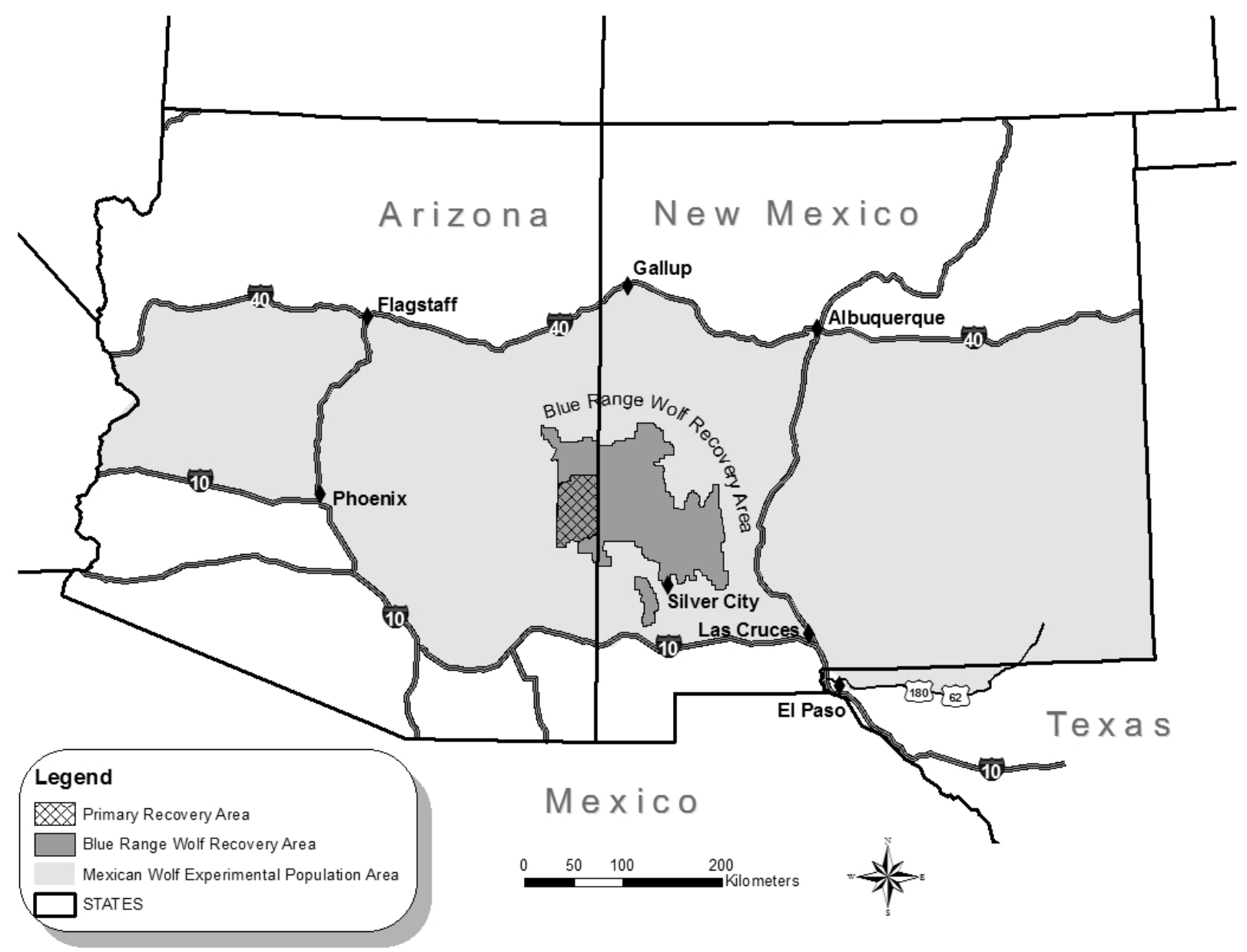

Figure 1. Mexican Wolf Experimental Population Area (MWEPA) and Blue Range Wolf Recovery Area (BRWRA) in eastern Arizona and western New Mexico from 1998 to 2014. Mexican wolves that established permanently outside of the BRWRA were translocated back into the boundary. Initial releases from captivity were only allowed in the Primary Recovery Zone. Translocations of wolves with wild experience and movements of wolves were allowed in entire BRWRA. In 2000, the White Mountain Apache Tribe allowed wolves to occupy the Fort Apache Indian Reservation. 


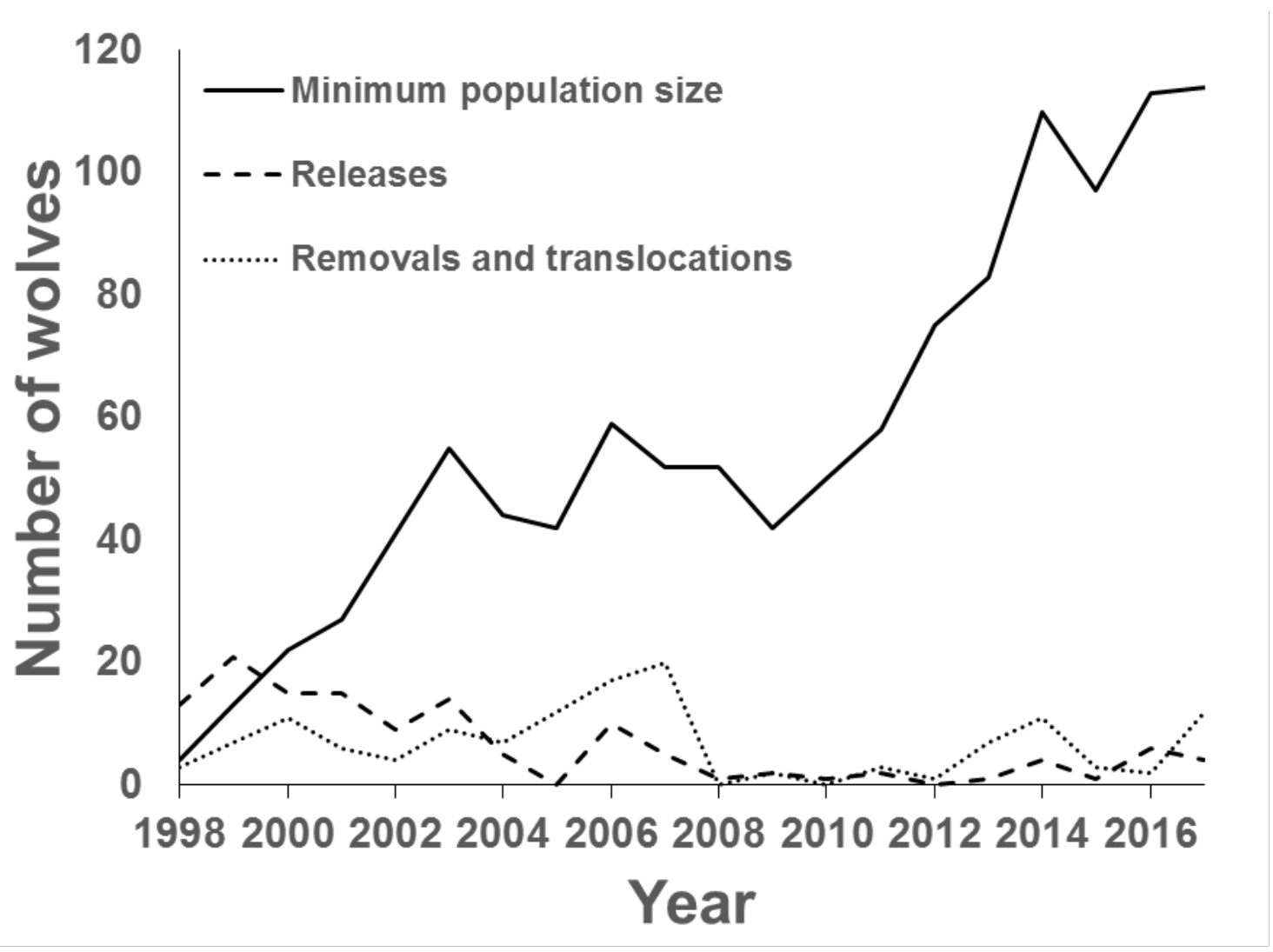

Figure 2. Number of wolves (minimum), wolf releases from captivity and wolf removals (lethal or to captivity) and translocations in the Mexican wolf reintroduction to the Blue Range Wolf Recovery Area in Arizona and New Mexico, USA, 1998-2017 (USFWS, unpublished data, 2017)

Survival rates of radio-collared wolves were estimated with Cox Proportional Hazards models (Cox, 1972) in R 3.3.1 (R Development Core Team, 2016) using the survival package (Therneau, 2015). Among released wolves, only data relevant to their first release was included in the survival analyses. For modeling purposes and to address the study objectives, the time period from which survival was estimated commenced at release or collaring and was terminated at death, disappearance, or first recapture. The USFWS designated an area where wolf releases would occur and wolves are permitted to occupy (U.S. Fish and Wildlife Service, 1998). Wolves that established residency outside of this area were translocated back into the BRWRA, and at this time they were right-censored in the survival analyses. We ran two separate survival analyses to compare survival rates when problem wolves were managed primarily through removals to when removals were reduced and diversionary feeding was increased. In the first analysis, we examined removal as a method for managing problem wolves, and thus, we treated these management actions as mortalities when they occurred. In the second analysis, problem wolves were instead right-censored at the time of the management action as an alternative to managing them through removals, thereby representing an indeterminate fate for these individuals. 
In the BRWRA population, annual surveys were conducted December-February to determine pack size and composition, and we used number of pups at this time (pup recruitment) as our metric for wolf reproduction. We define a pack as a group of greater than or equal to two wolves containing a minimum of one adult male or female. We refer to the primary adult male and female of a pack as the 'breeding' male and female, regardless of whether any reproductive activity has been confirmed between them, and any other adults in a pack as 'nonbreeding.' We summarized pup recruitment data by pack characteristics (i.e., age of breeding female or male, minimum pack size or nonbreeding adults present) or management approach (i.e., managing problem wolves through removals or diversionary feeding) to assess variation in pup recruitment. Management approach was based on population management during particular time periods rather than at the individual level.

\section{Population Models}

Our aim was to conduct a retrospective analysis to assess the influence of wolf origin (captiveor wild-born) and management approach (managing problem wolves through removals or diversionary feeding) on reintroduced wolf population performance by applying wolf origin-, management- or wolf state-specific survival probabilities to individual wolves. We created individual-based models in $\mathrm{R}$ 3.3.1 (R Development Core Team, 2016) to project population dynamics of reintroduced wolves. The models consisted of an array of packs and dispersers (individual wolves that do not belong to a pack), and were not spatially explicit besides treating packs as separate entities (i.e., each pack essentially represents a subpopulation). We assumed there was no spatial or temporal variation in prey availability and this was not considered in the model. Wolf states were dynamic and characterized by sex, age, status (breeding or nonbreeding adults) and pack membership. Survival was determined at an individual level and reproduction at a pack level. The model time step was 1 year, with events effectively occurring on the last day of each year; however, the execution of events in the model mimicked their chronological sequence over the year.

For each wolf origin and management approach category, we examined pack release strategies, including number and size of packs, within-pack age structure (number of breeding wolves, yearlings, and pups) and release frequency (number of release years and consecutive or alternating years). We did not vary sex structure of release cohorts because captive wolf managers have no control over birth sex, and release packs tend to be family units (i.e., breeding wolves with their current and previous year's offspring). We tested logistically realistic release strategies by varying pack size (small pack = two breeding wolves, large pack = two breeding wolves/one yearling/two pups or large pack with an additional yearling), number of packs initially (1-3) and subsequently $(\leq 3)$ released, and frequency (annually or biennially) and number of years (5, 10 [single small packs only] or 15 [single small packs only]) of subsequent releases. Sexes of released yearlings and pups were determined by sampling from a binomial distribution with an equal probability of producing a male or female. 
Survival rates were included in the models as random (stochastic) variables to account for demographic and environmental variation. These variables ranged from 0 to 1 , and so were sampled from a beta distribution (beta $[\alpha, \beta]$ ), with the shape parameters being estimated from mean survival $(\mu)$ and variance $\left(\sigma^{2}\right)$ (see table 1) using the method of moments (equations 1 and 2; DeGroot, 1970). This allowed us to simulate variability in demographic rates by resampling values at each time step.

$$
\begin{aligned}
& \alpha=\mu\left[\frac{\mu(1-\mu)}{\sigma^{2}(\mu)}-1\right] \\
& \beta=(1-\mu)\left[\frac{\mu(1-\mu)}{\sigma^{2}(\mu)}-1\right]
\end{aligned}
$$

Survival of each wolf to the next time step was determined using the survival rate associated with the wolf's origin or population management approach and/or the wolf's state during a given time step (see table 1). For example, when modeling survival of a released captive-born wolf, a captiveborn survival probability was applied to that wolf (regardless of its age) each year from release to when it left its release pack, whereas a wild-born pup survival probability was applied to a recruited pup for each year from collaring to when it left its natal pack. Alternatively, diversionary feeding was only effective when targeted towards wolves in packs (i.e., dispersers were too wide-ranging), and thus, the survival probability for a population when diversionary feeding was practiced (post-2008) was only applied to wolves while they were pack members. When a wolf dispersed from a pack, a new disperser survival probability was applied and if a disperser then joined an existing pack or created a new pack, a new survival probability was applied (see table 1). It was uncommon for wolves in the BRWRA population to live beyond 10 years; therefore, to account for natural wolf mortality from old age, survival for wolves that were older than $9,10,11$, and 12 years of age, were multiplied by 0.75 , $0.5,0.25$, and 0.1 , respectively. This resulted in a very low probability of any wolves older than 13 years in the population.

For each year modeled, for each pack with a breeding pair, the number of pups recruited was estimated by sampling from a Poisson distribution using the mean recruitment rate associated with the selected pack characteristic or management approach (see above), and this value was cast as an integer. Pup sexes were sampled from a binomial distribution with an equal probability of producing a male or female. Because pups are born in April, and pup recruitment is determined at the end of December, a 3-month wild-born pup survival probability was applied to these pups, and they enter the population at 1-year old. 
Table 1. Mean survival probabilities (variance in parentheses; $n=219$ wolves) and pup recruitment rates ( \pm standard error; $n=146$ potential litters) used in wolf population projection models, from Mexican wolves reintroduced to the Blue Range Wolf Recovery Area, New Mexico and Arizona, 1998-2014.

[Removals: Mortality, wolves translocated or removed due to nuisance behavior or depredations treated as mortalities; censor, manipulated nuisance wolves right-censored]

\begin{tabular}{llcc}
\hline \multirow{2}{*}{ Category } & \multicolumn{2}{c}{ Wolf/pack characteristic } & \multicolumn{2}{c}{ Demographic rate } \\
\cline { 3 - 4 } & & Removal = mortality & Removal = censor \\
\hline Wolf origin & & Survival & Survival \\
Captive-born & Released adults/yearlings/pups & $0.564(0.213)$ & $0.764(0.103)$ \\
Wild-born & Released adults/yearlings/pups & $0.685(0.115)$ & $0.797(0.057)$ \\
Management focus ${ }^{1}$ & & & \\
Removal & Released adults/yearlings/pups & $0.553(0.190)$ & $0.775(0.079)$ \\
& Wild-born pup & $0.731(0.103)$ & $0.819(0.056)$ \\
Diversionary feeding & Released adults/yearlings/pups & $0.755(0.075)$ & $0.782(0.058)$ \\
& Wild-born pup & $0.789(0.068)$ & $0.789(0.064)$ \\
Wolf state & & & \\
Wild-born pup & Wild-born pup & $0.769(0.080)$ & $0.798(0.062)$ \\
Disperser & Adult & $0.642(0.122)$ & $30.849(0.026)$ \\
Disperser to pack & Adult & $0.664(0.142)$ & $0.664(0.142)$ \\
Alpha female age & Pack size & Recruitment (pups/pack) \\
2-3 years old & $\leq 4$ wolves & $1.45 \pm 0.21$ & \\
& $>4$ wolves & $2.60 \pm 0.87$ & \\
4-8 years old & $\leq 4$ wolves & $1.69 \pm 0.21$ & \\
& $>4$ wolves & $2.50 \pm 0.30$ & \\
$>8$ years old & $\leq 4$ wolves & $0.60 \pm 0.43$ & \\
& $>4$ wolves & & \\
\hline
\end{tabular}

${ }^{1}$ Management of problem wolves.

${ }^{2}$ Dispenser joining an existing pack or creating a new pack.

${ }^{3}$ Survival estimated from only 5 wolves.

Data indicate that young wolves in the BRWRA population typically began dispersing from the pack in their second year, and by 4 years old most nonbreeding wolves had left the pack. Therefore, dispersal probabilities of $0.5,0.7$, and 0.9 were applied to wolves older than their first, second, and third years, respectively. Data from the BRWRA population show that dispersers occasionally encountered other dispersers of the opposite sex and formed a new pack. Because we did not have data on encounter probabilities for dispersing wolves, we include a 0.0325 probability of this occurring (i.e., of four cardinal directions, there is a $0.0625[0.25 \times 0.25]$ probability of two dispersers moving toward each other, and we applied an additional 0.5 probability that those two wolves will encounter each other and be of the opposite sex). In the model, if a breeding wolf died and there was an unrelated adult wolf in the pack of the opposite sex, that wolf became a breeder. Otherwise, breeding vacancies within a pack are frequently filled by dispersers, and if there were no eligible adults in the pack to fill a breeding vacancy, based on our data we applied a 0.8 probability that a disperser of the opposite sex will join the pack and become a breeder. If both breeding wolves die, and there were no other adults in the pack, death of any pups in the pack was forced, and the pack was dissolved. For packs with only one adult, we multiplied survival probability of any pups in the pack by 0.5 . 
Wolf population projection models were run for 25 years and replicated 1,000 times, and mean population size ( \pm 95 -percent confidence intervals) and number of packs were estimated. Population growth rate $(\lambda)$ was calculated according to equation 3.

$$
\lambda=\mathrm{N}_{f} /\left(\mathrm{N}_{i}+\mathrm{R}_{i-f}\right) .
$$

Here $\mathrm{N}_{f}$ is final population size, $\mathrm{N}_{i}$ is initial population size, and $\mathrm{R}_{i-f}$ is number of wolves released between $i$ and $f$.

\section{Release Strategies}

When examining release strategies, we divided them into three phases; initial (first release at year 0), heavy (at least 1 large pack released annually from years 1 to 5 or biennially from years 1 to 10 ) and light ( 1 small pack released annually from year 6 to 10 or 15 ). The number of wolves in the population after 25 years does not take into consideration the proportional contribution of released wolves to the population size. To evaluate release strategies, we accounted for the influence of the number and timing of wolf releases on the population by using a metric, release value (RV). This assigned a value to a release strategy, thereby allowing a quantitative comparison between two strategies to assess the relative value of a strategy to the population. Thus, comparative RVs for release strategies 1 and 2 are calculated in equations 4 and 5, respectively.

$$
\begin{aligned}
& \text { Release Strategy } 1 \text { Value }(\mathrm{RV} 1)=\frac{N 1_{T}}{\sum_{T}^{1} r 1_{t}\left(\frac{t}{T}\right)} \times \frac{N 1_{T}}{N 2_{T}} \\
& \text { Release Strategy } 2 \text { Value }(\mathrm{RV} 2)=\frac{N 2_{T}}{\sum_{T}^{1} r 2_{t}\left(\frac{t}{T}\right)} \times \frac{N 2_{T}}{N 1_{T}}
\end{aligned}
$$

Here, $T$ is the number of years over which the population is assessed, $N 1_{T}$ and $N 2_{T}$ are the wolf population sizes at $T$ for release strategies 1 and 2, respectively, $t$ is release year and $r 1_{t}$ and $r 2_{t}$ are the number of wolves released at $t$ for release strategies 1 and 2, respectively. Therefore, RV accounts for the number of wolves released at each time step, the elapsed time between each release and $T$, and the difference in resulting wolf populations between strategies (i.e., a higher RV score indicates greater benefit to the population of that release strategy). For example, if release strategy 1 has one release of $x$ wolves at $T$, release strategy 2 has one release of $x$ wolves at a time earlier than $T$ and $N 1_{T}=N 2_{T}=x$, then $\mathrm{RV} 1=1$ (i.e., the final wolf population can be wholly attributed to the recent release) and RV2 > RV1, because the $x$ wolves released at $t$ persisted over $T-t$ years, and thus, this would indicate that release strategy 2 may be more beneficial to the population. 
Within each wolf origin or management category, we used RVs to assess the influence of comparative strategies (i.e., pack composition, number of packs and release schedule) on wolf population size after 25 years. We began by conducting binary comparisons of within-phase components (e.g., initial, 2 versus 3 large packs; heavy, 1 versus 2 large packs annually; light, 1 small pack annually versus no releases), where all components of the other phases of the two strategies were equal. Patterns of the more beneficial components (i.e., those resulting in a better performing wolf population when also accounting for number and timing of wolves released) were similar across all categories, and thus, they were not considered separately thereafter. We then took the mean of the differences between RVs (MRVD) of each binary comparison within a set of the same components to evaluate the preferred strategy for that release phase. We arbitrarily defined MRVD $<1$ as having no advantage of either component, and the strategy that released fewer wolves was selected, $1 \leq \mathrm{MRVD}<$ 2 as offering only a slight benefit of one component, and the component with fewer releases was selected, and a component with MRVD $\geq 2$ had a distinct benefit, regardless of whether more wolves were released, and that component was selected. Finally, the most beneficial strategy from each phase was compiled into a single optimal release strategy, and this strategy was used in all subsequent population projection models.

\section{Results}

\section{Demographic Rates}

Overall annual wolf survival (mean \pm standard error) was $0.601 \pm 0.036(n=219$ wolves; 118 released; 101 wild-born). Wild-born wolves had higher survival than captive-born wolves (table 1). Survival in the population during period when removals were reduced and feeding was increased was 37 percent higher than during the period when problem wolves were being managed primarily through removals (table 1). Wolf survival rates were generally low, in part due to management (i.e., 13 percent of wolves were removed because of nuisance behavior $[n=16]$ or depredations $[n=13]$ ). Thus, we examined the impact on survival if these wolves were instead right-censored. This resulted in substantial increases in annual survival for captive- and wild-born wolves, and wolves managed through removals (pre-2009), yielding an overall survival of $0.765 \pm 0.033$. The distribution of data did not allow for survival estimates for wolf origin by management approach. Only two problem wolf removals ( 7 percent) occurred when wolves were managed primarily through diversionary feeding, perhaps in part due to very few wolves being released from captivity during this period, resulting in a higher proportion of wild-born wolves in the population, and thus, censoring these wolves did not improve survival rates (table 1).

From 69 unique packs (i.e., packs containing unique pairs of breeding adults) with a potential for 146 litters (i.e., from packs that were intact through breeding and whelping periods, regardless of whether reproductive activity was confirmed), mean pup recruitment was $1.76 \pm 0.13$ pups/pack. Shifting primary management of problem wolves from removals to diversionary feeding was associated with significantly higher recruitment (removals: $1.50 \pm 0.15$ pups/pack; diversionary feeding: $2.09 \pm 0.22$ pups/pack; $\left.t_{144}=-2.30 ; P=0.023\right)$. Pup recruitment varied most with minimum pack size $(\leq 4$ or $>4)$ and breeding female age $(2-3,4-8$ or $>8$ years $)$, and thus, recruitment data were summarized by these categories and used in the wolf population projection models. Minimum pack size had the strongest effect on pup recruitment, with the highest recruitment rates being exhibited by 2-8 year-old breeding females in packs with greater than 4 wolves, and the lowest rates being demonstrated by greater than 8 year-old breeding females in packs with less than or equal to 4 wolves (table 1). 


\section{Release Strategies}

The most beneficial phase-specific release strategy was an initial release of 3 large packs ( 2 packs, MRVD = 4.33), releases of 2 large packs annually from years 1 to 5 ( 1 large pack annually from years 1 to $5, \mathrm{MRVD}=5.04 ; 2$ large packs biennially from years 1 to $10, \mathrm{MRVD}=2.92$ ) and releases of 1 small pack annually from years 6 to 10 (no releases, MRVD $=4.54 ; 1$ small pack annually from years 6 to $15, \mathrm{MRVD}=1.37$ ). There was no substantial benefit to annual releases of an additional small pack $(\mathrm{MRVD}=1.83)$ during the heavy phase, nor adding a yearling to large packs $(\mathrm{MRVD}=$ 0.01 ) in both the initial and heavy phases. Therefore, for subsequent modeling we used a release strategy of 3 large packs released initially, followed by annual releases of 2 large packs for 5 years, then 1 small pack annually for 5 years and no wolf releases thereafter.

\section{Population Projections}

Releasing wild-born wolves led to a larger population after 25 years (mean [95 percent CI]: 39 [8-70] wolves in 10 packs) than releasing captive-born wolves (22 [0-57] wolves in 5 packs; fig. 3a, b), although CIs overlapped. The low survival rates when problem wolf removals were treated as mortalities (table 1) led to population decline, regardless of wolf origin $(\lambda=0.29-0.52$; fig. 3a, 3b). When these removals were instead right-censored, the higher survival rates (table 1) resulted in population growth when captive- or wild-born wolves were released $(\lambda=1.27-1.28)$. These adjusted survival rates were high enough to sustain population growth when releases of captive-born wolves were scaled back to one large and one small pack annually during the heavy phase, after which releases ceased $(\lambda=1.34)$, and population sustainability when terminating releases of wild-born wolves after 5 years $(\lambda=1.00)$. When problem wolves were managed mainly through removals (pre$2009)$, the population exhibited significant negative growth $(\lambda=0.05)$, approaching extinction after 25 years (4 [0-18] wolves in 1 pack; fig. 3c), whereas managing wolves through diversionary feeding (and not removing wolves) predicted population growth $(\lambda=1.03 ; 70$ [37-103] wolves in 18 packs; fig. 3d). When removals that we initially treated as mortalities were instead right-censored (i.e., to represent indeterminate fate), population growth was achieved during the period when problem wolves were managed through removals $(\lambda=1.59$; fig. $3 \mathrm{~d})$, and populations were sustainable even if releases were terminated after 5 years $(\lambda=1.33)$.

The poor performance of the BRWRA reintroduced wolf population was also due to low pup recruitment ( $1.76 \pm 0.13$ pups/pack). Therefore, we examined how improving reproductive performance might impact the wolf populations that were projected to decline, by running models where pup recruitment rates were augmented by $0.25,0.6$ (representing the observed increase in recruitment when management shifted away from removals to diversionary feeding), 0.75 and 1 pup(s)/pack. Increasing pup recruitment by $0.6 \mathrm{pups} / \mathrm{pack}$ led to population growth when captive- or wild-born wolves were released (captive-born $-\lambda=1.01$; wild-born $-\lambda=1.43$; fig. $3 \mathrm{a}, 3 \mathrm{~b}$ ). Small increases in pup recruitment benefited wolf populations to an extent whereby an increase of 0.6 pups/pack sustained population growth for released wild-born wolves, even if releases were reduced to one large pack annually during the heavy phase, then were discontinued $(\lambda=1.15)$. Populations derived from captive-born wolves also demonstrated growth, even when scaling back releases to one large pack annually for 5 years, with an increase of 0.75 pups/pack $(\lambda=1.13)$. 

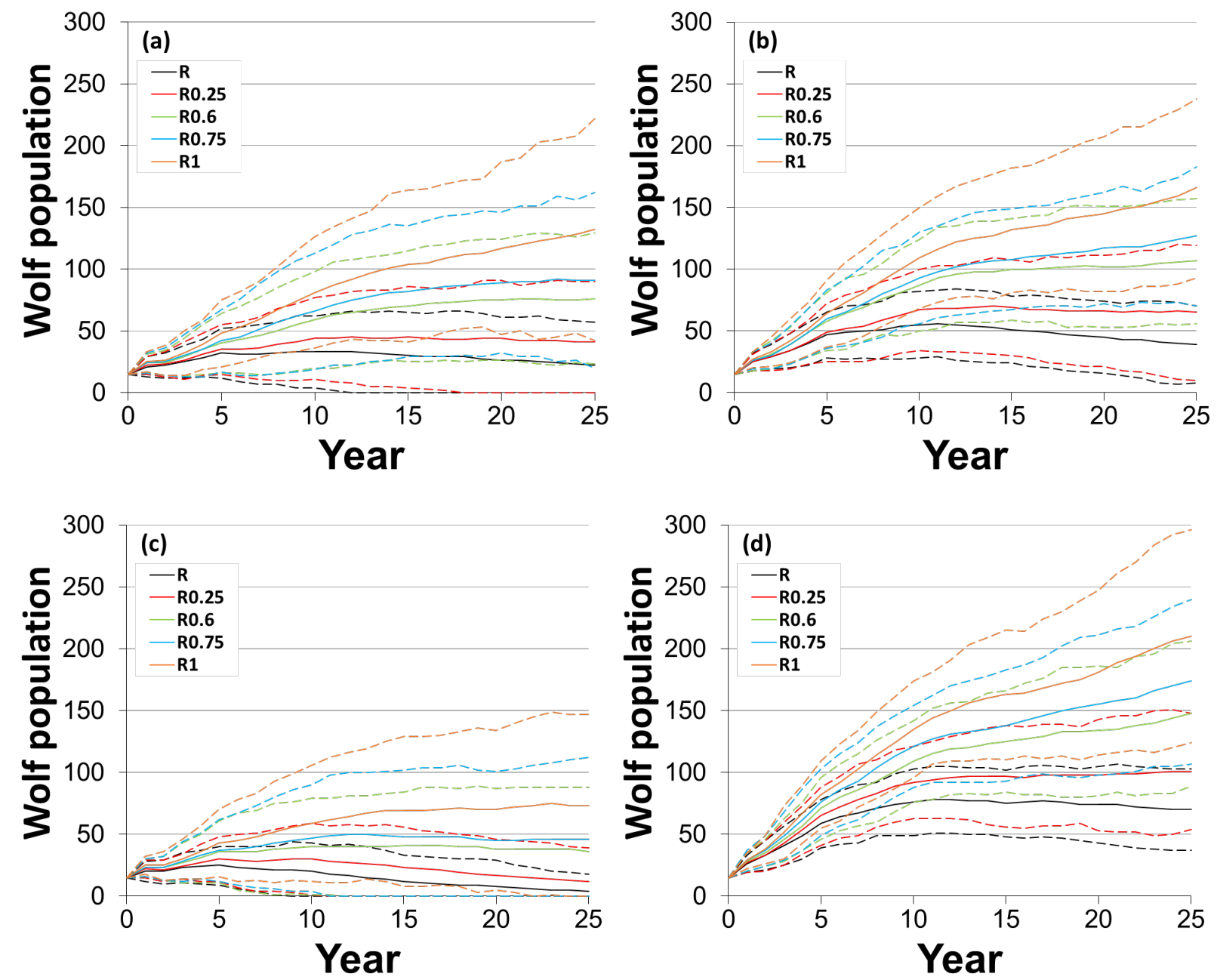

Figure 3. Mexican wolf population sizes (solid lines) and 95 percent confidence intervals (dashed lines) projected from individual-based models using data from Mexican wolves reintroduced to the Blue Range Wolf Recovery Area 1998-2014 in New Mexico and Arizona, USA, for released wolves that were (a) captive-born and (b) wildborn, and when problem wolves were managed through (c) removals and (d) diversionary feeding. All models incorporated a release strategy of an initial release of 15 wolves ( 3 packs), followed by 5 annual releases of 10 wolves ( 2 packs), then 1 breeding pair released annually for 5 years, after which wolf releases were discontinued. Graph lines show population estimates when pup recruitment rates were not augmented $(R)$, and were augmented by 0.25 (R0.25), 0.6 (R0.6), 0.75 (R0.75) and 1 (R1) pup(s)/pack. 


\section{Project Outcomes}

Our findings indicated that without post-release management intervention, the modeled reintroduced population of Mexican wolves was unsustainable. Low demographic rates resulting from problem wolf removal and poor pup recruitment led to a decline in our modeled population once releases ceased, regardless of any logistically plausible number of wolves released or origin of released wolves (captive- or wild-born). When primary management of problem wolves shifted from removal to diversionary feeding, survival and pup recruitment rates improved significantly and population growth was achieved. Indeed, during the period following termination of heaviest wolf releases and prior to the increase in diversionary feeding, the population hovered around 40-50 animals (fig. 2). These observed wolf populations were consistent with the population projections obtained from our models. Commencing in 2009, a change in management aimed at reducing nuisance- and depredationrelated removals in the BRWRA population, resulted in a significant increase in wolf numbers during this time. However, the reduction in removals coincided with the increase in diversionary feeding in the current wild population. This confounds any inferences that can be drawn about the relative contribution of reduced removals and diversionary feeding on the observed population growth.

Overall survival of collared wolves in this study was lower than in other wolf populations (e.g., see Fuller and others, 2003, p. 178). Moreover, in contrast to other populations (Fuller and others, 2003; Adams and others, 2008), this population is not connected to other large source populations, although it may eventually connect with the recently established population in Mexico, which is currently small. As such, this does not allow for sufficient immigration and reduces the capacity for the BRWRA population to recover as quickly as the Northern Rocky Mountain population of wolves. Despite wild-born wolves having higher survival than captive-born wolves, neither had survival rates that were sufficiently high to achieve population sustainability in our modeled population. This low survival can likely be attributed to a high proportion of wolf mortality in the BRWRA population being human-caused (>81 percent 1998-2011; Turnbull and others, 2013). Furthermore, treating problem wolf translocations and removals to captivity as mortalities in the survival analyses also contributed to the low survival rates. Indeed, when these wolves were instead right-censored (i.e., a proxy for not managing problem wolves through removals), improvement in survival led to population growth for both captive- and wild-born wolves, despite continued low pup recruitment (although had these wolves not been moved, they were highly likely to have eventually been lethally removed, either legally or illegally). These improved survival rates were sufficient for growth to be maintained in all populations, even when considering only the period following the termination of wolf releases (i.e., years 10-25). This suggests that if wolf behavior or livestock management practices could be modified to significantly reduce human-carnivore conflict, a sustainable reintroduced Mexican wolf population could exist. This is evident in the current Mexican wolf population, in that shifting management in 2009 away from removals and to diversionary feeding were associated with significantly higher population growth rates, and as such, wolf numbers have since more than doubled (fig. 2). In addition, very few wolves were released from captivity during this time, and wild wolves are less prone to nuisance-related removal (AMOC and IFT, 2005). As such, low removal rates and some level of diversionary feeding may have to be ongoing to sustain survival rates suitable for population growth. Another consequence of not managing problem wolves through removals, is that many of these wolves could die, regardless, from unnatural causes (e.g., legal and illegal shooting and vehicle collisions; Turnbull and others, 2013), which could prevent survival rates from reaching the levels predicted in our models. Management actions, including removal from the population, are a necessary component of large carnivore recovery from a sociological and biological standpoint, to increase social tolerance and reduce future conflicts (Bangs and others, 2005; Bradley and others, 2015). 
Mean pup recruitment in the BRWRA population was lower than that reported in other wolf populations (this study [year-end litter size] - 1.8; Yellowstone National Park [mid-winter litter size] 4.4 [Smith and others, 2015]; other studies [late fall/early winter litter size] - 1.9-5.4 [see Fuller and others, 2003, p. 177]). Pup recruitment augmentation simulations indicate that the population is sensitive to subtle changes in reproductive performance. Therefore, effecting slight improvements in pup recruitment could potentially lead to population sustainability. Pup recruitment increased by 0.6 pups/pack when problem wolves were managed through diversionary feeding, and recruitment augmentation simulations demonstrated that this increase would result in population growth, regardless of wolf origin. The cessation of removals alone could also increase pup recruitment as we found higher pup recruitment with increasing pack size. Thus more wolves in the pack would potentially contribute more food to pups. Providing diversionary food is only effective when pack movements are concentrated, and so attempts to extend the period of post-whelping food provision beyond late summer or early autumn when packs disperse from the den area would likely be ineffective. However, the benefits of increased pack size due to reduced removals would potentially benefit reproduction after packs dispersed from denning areas. Additionally, cross-fostering (i.e., introducing captive-born pups to a similar-aged wild litter to be raised as wild wolves) is a management technique aimed at enhancing genetic diversity, and can also increase pup recruitment. Cross-fostering has been successful in reintroduced red wolves (Canis rufus; Bartel and Rabon, 2013) and recent cross-fostering efforts in the BRWRA Mexican wolf population have resulted in genetic contributions to the population (U.S. Fish and Wildlife Service, 2015; Harding and others, 2016).

Maximizing efficacy of release strategies when reintroducing large carnivores involves tradeoffs between the positive effects of releases to increase population size and improve genetic diversity, and the greater risk that captive-raised individuals pose for human conflict, thereby eroding public support for the recovery. We found an optimal balance between the number and timing of wolves released and wolf population size after 25 years, was a strategy of an initial release of 15 wolves ( 3 packs), followed by annual releases of 10 wolves ( 2 packs) for 5 years, then one breeding pair annually for 5 years. Our model results also demonstrated that if pup recruitment could be increased by 0.75 pups/pack, captive- and wild-born releases could be reduced to 5 wolves ( 1 pack) annually for 5 years, after which releases could be discontinued, while still maintaining a sustainable population. However, management intervention is necessary to improve pup recruitment (e.g., diversionary feeding, cross-fostering, reduced removal rates), which in turn could offset the reduced management requirements of a scaled-back release schedule. In fact, the current Mexican wolf population demonstrated sustained growth when problem wolves were managed through diversionary feeding rather than removals (fig. 2). Releases may also contribute to genetic diversity, and fewer releases could compromise genetic variation in a reintroduced large carnivore population However, there is currently little evidence of inbreeding depression negatively affecting reproduction in the BRWRA population (Harding and others, 2016). 
Results from our models of the Mexican wolf reintroduction (based on data from 1998 to 2014) indicate that attempting to achieve a sustainable population in areas outside of the BRWRA will be challenging without ongoing management. Growth of our modeled wolf population was predicted with the higher survival rates when problem wolves were not managed through removals, but rather through the use of diversionary feeding in attempts to reduce livestock depredation. This is the current strategy for managing the population, and it has demonstrated growth for several years. However, the relative contribution of reduced removals and increased diversionary are unclear given the confounded timing in the shifting management strategies. Our results indicate that if pup recruitment can be improved for future reintroduction programs, the burden of wolf releases could be eased; however, reduced management efforts with fewer releases or when ceasing releases earlier are offset by the increased interventions necessary to improve reproduction (e.g., diversionary feeding, cross-fostering, other management actions to reduce human conflicts). Ultimately, some form of ongoing conservation management seems necessary to promote small populations of reintroduced Mexican wolves. Even large populations of wolves such as those in the Northern Rocky Mountain region of the northwestern United States continue to be intensively managed by lethal removal in response to depredations. This reaffirms the notion that intensive conservation management may be required to sustain a reintroduced population of large carnivores like the Mexican wolf on a human-dominated landscape. Large carnivore reintroduction programs could focus management on efforts to improve survival and reproduction and reduce conflict with humans and corresponding social pressures. The existing Mexican wolf population has demonstrated steady growth since 2009 when the management focus shifted away from removals. Alternatively, under exceptional circumstances, if there are release sites available where there is an abundance of prey, coupled with reduced densities of anthropogenic activity, these conditions could facilitate increases in demographic rates sufficient for growth.

The primary opposition to large carnivore reintroductions is rooted in controversy over their conflict with humans (Breitenmoser and others, 2001). In the modern global landscape, outside of protected areas it is inevitable that large carnivores will encounter humans, human settlement or domestic animals, and the level of conflict resulting will depend on negative impacts (i.e., safety, economic or recreational threat) and human tolerance (which is highly culture-dependent). This is why large carnivore reintroductions likely require some form of ongoing conservation management to sustain their populations. In particular, when reintroducing species that are founded on a dramatically small number of individuals (e.g., species that are critically endangered or extirpated in the wild), management actions to reduce conflict with humans and that facilitate increases in demographic rates, may have to occur over a longer period to establish a population that can persist. 


\section{Acknowledgments}

Data were collected by Arizona Game and Fish Department, New Mexico Department of Game and Fish, U.S. Fish and Wildlife Service, and White Mountain Apache Tribe. Colby Gardner and Allison Greenleaf assisted with the data. Funding was provided by the U.S. Geological Survey and U.S. Fish and Wildlife Service Science Support Partnership Program. We thank S. Breck, J. Heffelfinger, M. Mitchell, J. Oakleaf, S. Liley, and E. Rubin for their helpful comments on earlier drafts of this report.

\section{References Cited}

Adams, L.G., Stephenson, R.O., Dale, B.W., Ahgook, R.T., and Demma, D.J., 2008, Population dynamics and harvest characteristics of wolves in the Central Brooks Range, Alaska: Wildlife Monographs, v. 170, p. 1-25. https://doi.org/10.2193/2008-012.

Adaptive Management Oversight Committee and Interagency Field Team [AMOC and IFT]. 2005. Mexican wolf Blue Range reintroduction project 5-year review. Unpublished report to U.S. Fish and Wildlife Service, Region 2, Albuquerque, New Mexico, USA. http://www.fws.gov/southwest/es/mexicanwolf/MWNR_FYRD.shtml

Bangs, E.E., Fontaine, J.A., Jimenez, M.D., Meier, T.J., Bradley, E.H., Niemeyer, C.C., Smith, D.W., Mack, C.M., Asher, V., and Oakleaf, J.K., 2005, Managing wolf-human conflict in the northeastern United States, in Woodroffe, R., Thirgood, S., and Rabinowitz, A., eds., People and wildlifeConflict or coexistence?: Conservation Biology 9, Cambridge, United Kingdom, Cambridge University Press, p. 340-356, https://doi.org/10.1017/CBO9780511614774.022.

Bartel, R.A., and Rabon, D.R., Jr., 2013, Re-introduction and recovery of the red wolf in the southeastern USA, in Soorae, P.S., ed., Global re-introduction perspectives-2013. Further case studies from around the globe: Gland, Switzerland, IUCN/SSC Re-introduction Specialist Group, p. 107-115.

Bradley, E.H., Robinson, H.S., Bangs, E.E., Kunkel, K., Jimenez, M.D., Gude, J.A., and Grimm, T., 2015, Effects of wolf removal on livestock depredation recurrence and wolf recovery in Montana, Idaho, and Wyoming: The Journal of Wildlife Management, v. 79, no. 8, p. 1337-1346. https://doi.org/10.1002/jwmg.948.

Breitenmoser, U., Breitenmoser-Würsten, C., Carbyn, L.N., and Funk, S.M., 2001, Assessment of carnivore reintroductions, in Gittleman, J.L., Funk, S.M., Macdonald, D.W., and Wayne, R.K., eds., Carnivore conservation: Cambridge, United Kingdom, Cambridge University Press, p. 241-281.

Carrera, R., Ballard, W., Gipson, P., Kelly, B.T., Krausman, P.R., Wallace, M.C., Villalobos, C., and Wester, D.B., 2008, Comparison of Mexican wolf and coyote diets in Arizona and New Mexico: The Journal of Wildlife Management, v. 72, no. 2, p. 376-381, https://doi.org/10.2193/2007-012.

Cox, D.R., 1972, Regression models and life-tables: Journal of the Royal Statistical Society. Series B. Methodological, v. 34, p. 187-220.

DeGroot, M.H., 1970, Optimal statistical decisions: New York, New York, USA, McGraw-Hill.

Fuller, T.K., Mech, L.D., and Cochrane, J.F., 2003, Wolf population dynamics, in Mech, L.D., and Boitani, L., eds., Wolves-Behavior, ecology, and conservation: Chicago, Illinois, USA, University of Chicago Press, p. 161-191.

Harding, L.E., Heffelfinger, J., Paetkau, D., Rubin, E., Dolphin, J., and Aoude, A., 2016, Genetic management and setting recovery goals for Mexican wolves (Canis lupus baileyi) in the wild: Biological Conservation, v. 203, p. 151-159, https://doi.org/10.1016/j.biocon.2016.09.018. 
Hedrick, P.W., Miller, P.S., Geffen, E., and Wayne, R., 1997, Genetic evaluation of the three captive Mexican wolf lineages: Zoo Biology, v. 16, no. 1, p. 47-69, https://doi.org/10.1002/(SICI)10982361(1997)16:1<47::AID-ZOO7>3.0.CO;2-B.

Merkle, J.A., Krausman, P.R., Stark, D.W., Oakleaf, J.K., and Ballard, W.B., 2009, Summer diet of the Mexican gray wolf (Canis lupus baileyi): The Southwestern Naturalist, v. 54, no. 4, p. 480-485, https://doi.org/10.1894/CLG-26.1.

R Development Core Team, 2016, R: a language and environment for statistical computing. Vienna, Austria: R Foundation for Statistical Computing. Available from http://www.R-project.org.

Reed, J.E., Ballard, W.B., Gipson, P.S., Kelly, B.T., Krausman, P.R., Wallace, W.C., and Wester, D.B., 2006, Diets of free-ranging Mexican gray wolves in Arizona and New Mexico: Wildlife Society Bulletin, v. 34, no. 4, p. 1127-1133. https://doi.org/10.2193/00917648(2006)34[1127:DOFMGW]2.0.CO;2.

Smith, D., Stahler, D., Stahler, E., Metz, M., Cassidy, K., Cassidy, B., and McIntyre, R., 2015, Yellowstone National Park Wolf Project Annual Report 2014, National Park Service, Yellowstone Center for Resources, Yellowstone National Park, Wyoming, USA.

Therneau, T.M., 2015, A package for survival analysis in S. version 2.38. Available from http://www.R-project.org/package=survival.

Turnbull, T.T., Cain, J.W., III, and Roemer, G.W., 2013, Anthropogenic impacts to the recovery of the Mexican gray wolf with a focus on trapping-related incidents: Wildlife Society Bulletin, v. 37, no. 2, p. 311-318, https://doi.org/10.1002/wsb.247.

U.S. Fish and Wildlife Service, 1982, Mexican wolf recovery plan: U.S. Fish and Wildlife Service, Albuquerque, New Mexico, USA.

U.S. Fish and Wildlife Service, 1993, Biological evaluation for listed, proposed, and sensitive species of the forest-wide animal damage management plan on the Apache-Sitgreaves National Forests: U.S. Fish and Wildlife Service, Phoenix, Arizona, USA.

U.S. Fish and Wildlife Service, 1996, Reintroduction of the Mexican wolf within its historic range in the southwestern United States-Final Environmental Impact Statement: U.S. Fish and Wildlife Service, Albuquerque, New Mexico, USA.

U.S. Fish and Wildlife Service, 1998, The final Mexican wolf experimental rule: Federal Register, v. 63, p. 1752-1772.

U.S. Fish and Wildlife Service, 2015, Mexican wolf recovery program: progress report \#17. U.S. Fish and Wildlife Service, Albuquerque, New Mexico, USA. 
Publishing support provided by the U.S. Geological Survey Science Publishing Network, Tacoma Publishing Service Center

For more information concerning the research in this report, contact the Leader, Washington Cooperative Fish and Wildlife Research Unit U.S. Geological Survey

Fishery Sciences Building, Box 355020

University of Washington

Seattle, Washington, 98195

https://www.coopunits.org/Washington/ 
\%ั

을

‥

웅

פ 